Morais, JMP, Silva, AM, Barboza, EN, Silva, EM \& Oliveira, BB (2020). Analysis of pathological manifestations in reinforced concrete structures: a review. Research, Society and Development, 9(7): 1-32, e759974964.

\title{
Análise de manifestações patológicas em estruturas de concreto armado: uma revisão
} Analysis of pathological manifestations in reinforced concrete structures: a review Análisis de manifestaciones patológicas en estructuras de hormigón armado: una revisión

Recebido: 26/05/2020 | Revisado: 27/05/2020 | Aceito: 28/05/2020 | Publicado: 11/06/2020

João Marcos Pereira de Morais

ORCID: https://orcid.org/0000-0001-8097-9607

Universidade Regional do Cariri, Brasil

E-mail: joaomarcostecnologo@gmail.com

Andreane Martin da Silva

ORCID: https://orcid.org/0000-0002-7236-4175

Universidade Regional do Cariri, Brasil

E-mail: Martins.andreane@gmail.com

Eliezio Nascimento Barboza

ORCID: https://orcid.org/0000-0001-8100-9389

Instituto Federal de Educação, Ciência e Tecnologia do Ceará, Brasil

E-mail: eliezio1999@outlook.com

Eduarda Morais da Silva

ORCID: https://orcid.org/0000-0001-9463-8280

Instituto Federal de Educação, Ciência e Tecnologia do Ceará, Brasil

E-mail: eduardamoraisengenharia@gmail.com

Bruno Barbosa de Oliveira

ORCID: https://orcid.org/0000-0002-1279-1431

Universidade Regional do Cariri, Brasil

E-mail: bruno.barbosa@urca.br

\section{Resumo}

O termo patologia abordado na engenharia civil compreende o estudo da origem, tratamento dos problemas das edificações, representando danos estéticos, redução do desempenho da 
edificação, podendo prejudicar a funcionalidade do edifício ou seus subsistemas. Danos em estruturas de concreto armado podem ser evitados ainda na fase projetos, várias obras apresentam problemas com as manifestações patológicas, problemas esses que podem ser muito onerosos sua recuperação. Nesse contexto, o presente artigo objetiva por meio de um estudo de revisão de literatura analisar as principais incidências patológicas em estruturas de concreto armado, além de propor soluções práticas dos problemas, respostas essas apresentadas pelos autores das respectivas obras dos estudos de caso analisados. Esse trabalho baseou-se em trabalhos da base de dados de literatura científica Google Acadêmico, totalizando 15 estudos, utilizando-se as publicações de janeiro de 2009 a janeiro de 2020, tendo as seguintes palavraschave: Patologia de edificações, análise patológica, construção civil, concreto armado e maiores incidências. Por meio da literatura abordada, foi possível verificar que das patologias analisadas, a mais frequente é a corrosão da armadura, estando presente 100\% dos trabalhos analisado e em seguida destacam-se as incidências de patologias do tipo fissura e manchas, com $73 \%$ e $60 \%$, respectivamente. Foi verificado que as trincas representam 53\% das manifestações patológicas encontrada nas obras; Eflorescencia (47\%); Flambagem (27\%) e Carbonatação $(20 \%)$.

Palavras-chave: Construção civil; Patologias; Peças estruturais; Maiores incidências.

\section{Abstract}

The term pathology addressed in civil engineering comprises the study of the origin, treatment of building problems, representing aesthetic damage, reduction of building performance, and may impair the functionality of the building or its subsystems. Damage to reinforced concrete structures can be avoided even in the projects phase, several works present problems with pathological manifestations, problems that can be very costly their recovery. In this context, this article aims through a literature review study to analyze the main pathological incidences in reinforced concrete structures, in addition to proposing practical solutions to the problems, answers presented by the authors of the respective works of the case studies analyzed. This work was based on papers from the Google Acadêmico scientific literature database, totaling 15 studies, using the publications from January 2009 to January 2020, having the following keywords: Pathology of buildings, pathological analysis, civil construction, reinforced concrete and higher incidences. Through the literature addressed, it was possible to verify that of the pathologies analyzed, the most frequent is corrosion of the reinforcement, being present $100 \%$ of the studies analyzed and then stand out the incidences of pathologies of the type fissure and spots, with $73 \%$ and $60 \%$, respectively. It was verified that the cracks represent $53 \%$ of the 
pathological manifestations found in the works; Eflorescencia (47\%); Buckling (27\%) and Carbonation (20\%).

Keywords: Construction; Pathologies; Structural parts; Higher incidences.

\section{Resumen}

El término patología abordada en ingeniería civil comprende el estudio del origen, el tratamiento de los problemas de construcción, que representa el daño estético, la reducción del rendimiento del edificio, y puede afectar a la funcionalidad del edificio o de sus subsistemas. Los daños a las estructuras de hormigón armado se pueden evitar incluso en la fase de proyectos, varias obras presentan problemas con manifestaciones patológicas, problemas que

pueden ser muy costosos su recuperación. En este contexto, este artículo tiene como objetivo a través de un estudio de revisión de la literatura analizar las principales incidencias patológicas en estructuras de hormigón armado, además de proponer soluciones prácticas a los problemas, respuestas presentadas por los autores de las respectivas obras de los estudios de caso analizados. Este trabajo se basó en trabajos de la base de datos de literatura científica de Google Acad-mico, que suman 15 estudios, utilizando las publicaciones de enero de 2009 a enero de 2020, con las siguientes palabras clave: Patología de edificios, análisis patológico, construcción civil, hormigón armado y mayores incidencias. A través de la literatura abordada, fue posible verificar que de las patologías analizadas, la más frecuente es la corrosión del refuerzo, estando presente el $100 \%$ de los estudios analizados y luego destacar las incidencias de patologías del tipo fisura y manchas, con $73 \%$ y $60 \%$, respectivamente. Se verificó que las grietas representan el 53\% de las manifestaciones patológicas encontradas en las obras; Eflorescencia (47\%); Pandeo (27\%) y Carbonación (20\%).

Palabras clave: Construcción; Patologías; Piezas estructurales; Mayores incidencias.

\section{Introdução}

A finalidade de avaliar e prever o desempenho e a durabilidade das edificações originouse da necessidade de proporcionar, concomitantemente, o conforto e a segurança aos usuários (Rios et al., 2020). Gonçalves (2015) afirma pelos atrasados métodos ainda utilizados na construção civil e pela resistência a inovações tecnológicas, é perceptível a rápida manifestação patológica nas edificações após ser construída. Destaca-se manifestações patológicas em estruturas de concreto armado, no qual podem afetar a qualidade do projeto, reduzindo a 
resistência à ruptura, a vida útil do empreendimento e a capacidade de suportar as influências externas (Ferreira, 2018).

O concreto é um dos materiais mais importante e presente na construção civil (Granato, 2012), sendo constituído basicamente pela junção de cimento, água, agregado miúdo e agregado graúdo, como também pode ser adicionado resíduos e aditivos químicos (Kaefer, 1998). Ao adicionar armadura no concreto, cria-se uma estrutura de concreto armado. Esse tipo de estrutura foi criado com a necessidade de se aliar as qualidades da pedra (resistência à compressão e durabilidade) com as do aço (resistências mecânicas), proporcionando a necessária proteção do aço contra a corrosão (Bastos, 2006).

De acordo com Souza e Ripper (1988), o concreto é um dos materiais mais consumido do mundo, em decorrência da grande procura pelo uso do concreto armado, ocasionado pela sua felicidade de obtenção e por sua eficácia em obras de pequeno, médio e grande porte. Consequentemente, o seu uso sem as devidas precauções pode desencadear diversas manifestações patológicas, tais como: fissuras, trincas, flambagem, corrosão, desagregação, eflorescência, manchas, muitas vezes causadas por mal execução, por materiais de má qualidade, por não respeitar as etapas da execução ou até mesmo pelo uso inapropriado da estrutura (Cirino et al., 2020).

Diante dessa problemática, surge o campo de estudo da engenharia, através de pericias e inspeções técnicas, destinada a especificamente analisar e propor soluções cabíveis para tais anomalias, visto que por se tratar de elemento estrutural há o iminente de risco de vida aos que utilizam desses elementos (Morais, 2017). Segundo Santos (2014), os problemas patológicos podem ser ocasionados pela manutenção inadequada ou falta de manutenção, têm sua origem no desconhecimento técnico, na incompetência e em problemas econômicos, originando-se uma série de erros sucessivos, desencadeando novos problemas e riscos. Para conter esses e outros danos a engenharia é capaz de mostrar métodos que possam salientar modos viáveis de reformar ou até mesmo de reparar o prejuízo existente.

Nesse sentido, o presente artigo objetiva por meio de um estudo de revisão de literatura analisar as principais incidências patológicas em estruturas de concreto armado, além de propor soluções práticas dos problemas, respostas essas apresentadas pelos autores das respectivas obras dos estudos de caso analisados. 


\section{Patologia em Estrutura de Concreto Armado}

De acordo com Andrade e Silva (2005), o procedimento para a realização de uma edificação está compreendido em quatro fases: pré-projeto, projeto, execução e o habite-se, a ocorrência de erros em uma dessas etapas podem acarretar sérios danos e insegurança. Os autores corroboram ao afirmar que o termo patologia, surgiu na medicina e é empregado na construção civil quando se refere a perda ou queda de desempenho parcial ou completa da estrutura. Patologia é oriunda do grego e significa literalmente "estudo da doença", onde Pathos significa doença e Logos por sua vez quer dizer estudo (Andrade \& Silva, 2005; Borges, 2008).

Para entender o sentido de uma estrutura de concreto armado, Helene (2001) afirma que é preciso antes ter noção de durabilidade, afinal a estrutura necessita de uma vida útil mais prolongada. A durabilidade consiste na capacidade de a estrutura resistir às influências ambientais previstas e definidas em conjunto pelo autor do projeto estrutural e pelo contratante, no início dos trabalhos de elaboração do projeto (NBR 6118, 2014).

A etapa de execução das estruturas é de extrema importância nas definições de condições de durabilidade que a estrutura vai apresentar durante sua vida útil. Nesse contexto, os principais fatores que mais influenciam negativamente na durabilidade das estruturas de concreto armado nas obras são: as características do concreto, materiais impróprios, condições de carregamento e de exposição (Pfeil, 1984). Para um bom projeto estrutural ser considerado definitivamente concluído e estar apto a ser executado, Olivari (2003) afirma que é necessário que seja realizado com riqueza de detalhes em suas pranchas, para assim impedir ou até mesmo minimizar equívocos quanto a sua execução.

Os principais erros em obras que usa o concreto armado como forma estrutural consistem basicamente em falta de detalhamento, erro de dimensionamento, desprezo do efeito térmico, divergência entre os projetos elétricos, hidráulicos, sobrecarga na estrutura não prevista, determinação incorreta de cobrimento e concreto deficiente, desencadeando uma série de novos problemas patológicos, como: manifestação de fissuras, eflorescência, manchas, trinca, carbonatação e flambagem (Zanzarine, 2016; Munaro \& Possan, 2017).

Muitas das manifestações patológicas ocorrem devido à falta da cura do concreto. Souza e Ripper (1988) corroboram ao afirmar que, enquanto não atingir a resistência satisfatória, o concreto deve ser protegido contra mudanças bruscas na temperatura, secagem rápida, exposição direta ao sol, a chuvas fortes, agentes químicos, bem como contra choques e vibrações que possa produzir fissuração na massa de concreto ou prejudicar sua aderência a armadura. 
Existem diversas formas para se realizar uma cura bem feita do concreto, técnicas como adicionar mantas com grande índice de umidade sobre a face das lajes, assim como também pode-se adicionar areia molhadas sobre essas superfícies, ou até mesmo serragem de madeira umedecidas, sempre evitando ao máximo o contato direto da estrutura com o sol. Nos casos em que se trata de uma estrutura maior ou mais volumosa, a cura deve ser mais intensificada, prolongada por mais dias, algo entre sete a nove dias após o lançamento do concreto (Andolfato, 2002). É importante saber que se for preciso interromper uma concretagem, só é recomendado retomá-la somente três dias após à interrupção, visto que o adensamento na retomada pode gerar vibrações em toda a estrutura fazendo com o que a armadura se disperse do concreto.

\subsection{Fissuras}

De acordo com Morais (2017), as fissura são aberturas longitudinais de pequena espessura permitindo a entrada de ar, no qual pode entrar em contato com a armadura e corroêlo. São vários os tipos de fissuras tais como: fissuras por retração hidráulica, fissura devido a variação de temperatura, fissura devido a flexão, fissura devido ao cisalhamento, fissuras devido a compressão e fissuras devido a punção. Esse tipo de patologia é tão antigo quanto os próprios edifícios em que neles se manifestam, em obras que utilizam cimento é comum esse aparecimento de anomalias, seja ainda recente o lançamento do concreto na forma ou depois de algum período (Corsini, 2010).

As fissuras que se manifestam em estruturas de concreto armado são resultados de vários processos em que se apresentam erros e podem se apresentar antes ou depois do endurecimento do concreto (Silva, 1996). As manifestações patológicas no concreto ainda fresco pode ser proveniente de assentamento plástico, de retração da superfície decorrida de rápida evaporação da água, movimentação das fôrmas ou dessecação superficial, já as fissuras apresentadas no estado endurecido podem se apresentar por vários fatores, dentre eles, térmicos, físicos, químicos ou por influencias externas (Molin, 1988).

Segundo Gonçalves (2015), as fissuras são classificadas como ativas ou passivas, as ativas são as que alteram suas características físicas quando varia a temperatura com movimentos de dilatação e contração aumentando, reduzindo sua espessura. As fissuras do tipo passivas se apresentam de uma forma estáticas não apresentam variações em tamanho nem espessura (Zanzarine, 2016). De acordo com Pfeil (1984), as variações de temperatura podem causar deformações na estrutura de concreto, as chamadas dilatações térmicas, por 
(CC BY 4.0) | ISSN 2525-3409 | DOI: http://dx.doi.org/10.33448/rsd-v9i7.4964

consequência dessa variação o concreto pode fissurar, as fissuras também podem ser ocasionadas por tensões de tração devida a pequena resistência à tração que o concreto suporta.

\subsection{Trincas}

Trinca na construção civil é definida como uma abertura ou fratura superficial linear no concreto, de tamanho igual ou superior $6 \mathrm{~mm}$ (Quadro 1), caso esse abrimento seja inferior à medida estipulada é caracterizada como fissura (NBR 15575, 2013). As medidas nem sempre são seguidas à risca pelas normas, outras interpretações são feitas e têm muita significância em termos de aceitações.

Quadro 1: Classificação de espessura da abertura.

\begin{tabular}{|c|c|}
\hline Anomalia & Abertura (mm) \\
\hline Fissura & Até 0,5 \\
\hline Trinca & De 0,5 a 1,5 \\
\hline Rachadura & De 1,5 a 5,0 \\
\hline Fenda & De 5,0 a 10,0 \\
\hline Brecha & Acima de 10,0 \\
\hline
\end{tabular}

Fonte: Oliveira (2012).

Conforme Oliveira (2012), fissuras e trincas são terminologias distintos, porém capazes de causar confusões quanto à sua nomenclatura, então, essa diferenciação se dá por meio da espessura apresentada, sendo que até, 0,5 milímetro essa abertura é considerada uma fissura, entre 0,5 e 1,5 milímetros de abertura pode-se considerar uma trinca, uma rachadura é apontada por espaçamento de 1,5 à 5,0 milímetros, a fenda possui abertura entre 5 a 10 milímetros, pra qualquer abertura maior que 10 milímetros, considera-se uma brecha.

Granato (2012) complementa ao afirmar, que as trincas comprometem a estética, ocasionado muitas vezes pelo preparo inadequado da argamassa e pela hidratação da cal não completa, pois argamassa com alta relação água/cimento, ou mesmo quando cimento em excesso em sua composição, falta de Intertravamento (amarração) dos blocos cerâmicos, revestimento muito expeço, a não obediência à abertura para encuhamento, falta de juntas de dilatação, essas trincas podem se apresentar em grande variedade de formatos e aberturas.

Grande parte dos problemas com trincas está diretamente relacionado com a má execução das juntas ou até mesmo inexistência delas, se trata das juntas de dilatação térmica, 
elas atuam como divisoras das peças de todos os elementos construtivos (pilares, vigas, lajes e alvenarias) e tem a função de não permitir que a variação de temperatura cause movimentação, evitando patologias (Oliveira, 2012).

As trincas no concreto podem estar presentes em todas as fases da obra, caso seja executado de forma errada ou mal dimensionado na fase do projeto estrutural, pois de acordo com Borges (2008), nas fundações, as trincas podem ser provocadas por recalques diferenciados, visto que as tensões de grande intensidade na sua estrutura pode provocar o aparecimento de trincas.

\subsection{Eflorescência}

A eflorescência é um dano a estrutura que traz prejuízo a estética, ainda mais quando há o contraste de sais com outros substratos (Menezes, Ferreira H. S., Neves \& Ferreira H. C., 2006). Esse tipo de anomalia é resultante da exposição do material a infiltração, água ou intempéries, podendo em alguns casos, além de alterar a aparência física, seus sais constituintes podem ser agressivos e resultar em degradação profunda da estrutura, com possibilidade de atingir o aço e causar sérios problemas (Granato, 2012). Pela análise química da eflorescência, é verificado que essa manifestação patológica é ocasionada por sais de metais alcalinos tais como potássio e sódio, além de alcalino-ferrosos com magnésio e cálcio quando esses em uma solução aquosa (Dias, 2012).

\subsection{Deflexão lateral (Flamblagem)}

Os elementos esbeltos no sentido vertical são chamados de pilares ou colunas e a deflexão lateral que esses elementos estão sujeitos a sofrer são chamados de flambagem. Devido à grande importância da função estrutural que essa peça abrange, se faz necessário muita atenção ao dimensioná-la, haja visto um risco maior e iminente quando se constrói sem qualquer estudo de definição de armadura, recobrimento e espaçamento do aço (Oliveira Buffoni, 2004). A carga máxima suportada pelo pilar é chamada de carga crítica, na ocasião de adicionar alguma força entra na estrutura certamente ela gera a flambagem. É importante saber também que a deflexão lateral (flambagem) sempre ocorrerá em torno do seu eixo principal bem no seu ponto mais frágil (Hibbeler, 2010). 


\subsection{Manchas}

De acordo com Helene (1986), algumas empresas de matérias de construção, almejando lucro sobre à redução dos custos de produção, aplicam desmoldantes de péssima qualidade e baixo custo, esse material sem qualidade geralmente apresentam manifestações patológicas que requerem a aplicação de pasta de cimento na superfície da estrutura, uma forma de esconder o problema, acarretando assim muitas horas dos operários e consequentemente gasto extra.

Esses desmoldantes podem deixar marcas no concreto, manchas que mesmo que maquiadas com argamassa, vem à tona com o tempo. Esse tipo de desmoldante geralmente é banha de animal óleos e graxas, sendo caraterizados por ser produtos poucos solúveis em água, e quando expostos a chuvas, podem ser levados e por consequência causam manchas na superfície das peças (Milani, Boesing, Philippsen \& Miotti, 2012).

\subsection{Carbonatação}

A carbonatação é a capacidade do gás carbônico $\left(\mathrm{CO}_{2}\right)$ que se encontra na atmosfera e adentra os poros do concreto, podendo atingir a armadura e danificá-la (Hoppe Filho, 2008). Com a combinação do $\mathrm{CO}_{2}$ e o hidróxido de cálcio $\left(\mathrm{Ca}(\mathrm{OH})_{2}\right)$ presente na pasta do cimento, forma-se o carbonato de cálcio $\left(\mathrm{CaCO}_{3}\right)$, com isso o desaparecimento do hidróxido de cálcio $\left(\mathrm{Ca}\left(\mathrm{OH}_{2}\right)\right)$ na parte de dentro dos poros da pasta do cimento hidratado faz com o que baixe o ph do concreto (geralmente está entre 12,5 e 14) para valores menores, algo em torno de 9 , resultando assim na carbonatação do concreto (Santos, 2014).

São várias as formas de verificar o quanto à frente de carbonatação está avançado no concreto, métodos como a difração de raios-x, análise térmica diferencial e termogravimétrica. Entretanto, o método prático mais utilizado em obras é através de indicadores de $\mathrm{PH}$, que é a base de fenolftaleína. O teste é realizado aplicando o produto diretamente na superfície da estrutura a ser analisada, instantes depois da aplicação já é possível notar a mudança na cor do concreto, a fenolftaleína se transforma em uma coloração róseo-avermelhada na região em que não está carbonada (Pfeil, 1984).

\subsection{Corrosão da armadura}

Segundo Freire (2005), existem dois grandes tipos de corrosão, a de natureza eletroquímica e química. A autora afirma que a uma enorme diferença entre ambas, na 
eletroquímica os elétrons movimentam-se diretamente no aço, migrando da região do ânodo para o cátodo, realizando uma solução iônica quando se completa o circuito elétrico através do eletrólito, no caso da corrosão química, a película de óxido que se faz presente sobre o ferro atua imediatamente como condutora de elétrons e íons.

A corrosão química é também conhecida por corrosão seca ou oxidação, e se processa por uma reação gás/metal, formando uma película de óxido (Nascimento, 2015). É um processo lento, não provocando estragos relevantes nas superfícies metálicas, geralmente está associado a altas temperaturas, podendo ocorrer na temperatura ambiente, em meio gasoso e em alguns meios líquidos. Em geral, acarreta uma corrosão homogênea na superfície do metal, não existindo reações de oxidação e redução e por conseguinte, geradores de correntes elétricas (Freire, 2005).

A perda de seção do aço se caracteriza devido ataques provocados pela corrosão química. Contribuindo com essas informações, Souza e Ripper (1988) afirmam que, muito se sabe sobre a importância do cobrimento em estruturas de concreto armado, ela pode ser decisiva em termos de proteção à armadura, sendo recomendável cobrimento maior que $3 \mathrm{~cm}$. Helene (2001) complementa, que além de um cobrimento nos parâmetros estabelecidos por norma, é imprescindível que o concreto possua em sua composição impermeabilizantes a fim de inibir a infiltração dos agentes agressivos à armadura.

\section{Metodologia}

\subsection{Tipo de pesquisa}

Conforme caracterizam Pereira et al. (2018), do ponto de vista da natureza, esse trabalho trata-se de uma pesquisa básica. Pelas perspectivas de abordagem, é uma pesquisa qualitativa. Analisando os objetivos essa pesquisa é exploratória. Em relação aos procedimentos técnicos é do tipo revisão bibliográfica.

\subsection{Realização do estudo critérios de amostragem utilizados}

O presente artigo de revisão baseou-se em trabalhos da base de dados de literatura científica Google Acadêmico, utilizando-se as publicações de janeiro de 2009 a janeiro de 2020, tendo as seguintes palavras-chave: Patologia de edificações, análise patológica, construção 
civil, concreto armado e maiores incidências. Os dados foram obtidos por meio de publicações em revistas, Trabalhos de Conclusão de Curso, dissertações de mestrado e tese de doutorado.

Para organizar as informações dos trabalhos selecionados da base dados, contidas em 15 publicações, foi utilizada a leitura flutuante dos títulos e resumos dos trabalhos bem como os resultados apresentados. A métrica utilizada para a seleção das literaturas foi a aplicação direta da presença de patologias em concreto armado, com ênfase nas publicações que abordam sugestões de correção. Os dados foram registrados em forma de tabela para os estudos selecionados.

\subsection{Procedimentos metodológicos}

De acordo com Gil (2008), para se realizar uma pesquisa ou revisão bibliográfica a primeira iniciativa é a organização do problema a ser pesquisado, para posteriormente avaliar e aplicar todo o máximo do material bibliográfico disponível, uma vez que o tema deve conter relevância tanto teórica como prática e proporcionar interesse de ser estudado.

O conteúdo inicial do referencial teórico são os conceitos de patologia em concreto armado nas edificações. Essas informações foram organizadas pelos tipos de manifestações patológicas, na seguinte sequência; Fissuras, Trincas, Eflorescência, Deflexão lateral (Flambagem), Manchas, Carbonatação e Corrosão da armadura. Tais definições são essenciais para melhor entendimento acerca das problemáticas abordadas e apresentadas no decorrer desse trabalho, como também ajudará a entender e demonstrar as origens, propor possíveis medidas preventivas e mostrar como as implicações ocasionadas por essas anomalias podem trazer perigo ao bem estar físico dos seus usuários.

Nesse contexto, serão apresentados no decorrer desse estudo, análises dos resultados e discussões sobre estudos realizados por Santos (2014), Moreira (2009), Possan e Munaro (2017), Santos (2014), Iantas (2010), Silva (2011), Trindade (2015), Gonçalves (2015), Silva (2018), Martins e Fioriti (2016), Lottermann (2013), Melo, Andrade e Paula (2009), Brito (2017), Santos (2012), Zuchetti (2016), representados respectivamente por Obra 1, Obra 2, Obra 3 e assim sucessivamente, o Quadro 2 apresenta as manifestações patológicas estudadas pelos autores. 
Quadro 2: Descrição das obras analisadas.

\begin{tabular}{|c|c|c|}
\hline Obra & Autor & Descrição \\
\hline 01 & Santos (2014) & $\begin{array}{l}\text { Análise de manifestação patológica em um prédio } \\
\text { residencial de } 750 \mathrm{~m}^{2} \text {. }\end{array}$ \\
\hline 02 & Moreira (2009) & $\begin{array}{l}\text { Estudo das manifestações patológicas na produção de } \\
\text { pré-fabricados de concreto. }\end{array}$ \\
\hline 03 & Possan e Munaro (2017) & $\begin{array}{l}\text { Estudo das manifestações patológicas na produção de } \\
\text { pré-fabricados de concreto, produções de pré } \\
\text { moldados. }\end{array}$ \\
\hline 04 & Santos (2014) & $\begin{array}{l}\text { Análise de manifestação patológica em um prédio } \\
\text { abandonado no Distrito Federal. }\end{array}$ \\
\hline 05 & Iantas (2010) & $\begin{array}{l}\text { Análise de patologias estruturais em edificação de } \\
\text { gestão pública, uma instituição escolar de } 864 \mathrm{~m}^{2} \text {. }\end{array}$ \\
\hline 06 & Silva (2011) & $\begin{array}{l}\text { Análise de manifestações patológicas em uma } \\
\text { residência unifamiliar de } 340 \mathrm{~m}^{2} \text {. }\end{array}$ \\
\hline 07 & Trindade (2015) & $\begin{array}{l}\text { Análises patológicas referentes a juntas de dilatação } \\
\text { em obra privada. }\end{array}$ \\
\hline 08 & Gonçalves (2015) & $\begin{array}{l}\text { Análise de manifestações patológicas em um edifício } \\
\text { unifamiliar de } 20 \text { pavimentos tipo. }\end{array}$ \\
\hline 09 & Silva (2018) & $\begin{array}{l}\text { Análise das patologias construtivas em uma residência } \\
\text { unifamiliar na cidade de Juazeiro do Norte-CE. }\end{array}$ \\
\hline 10 & Martins e Fioriti (2016) & $\begin{array}{l}\text { Análise de manifestações patológicas em sistemas } \\
\text { estruturais em edificação pública de } 4.146 \mathrm{~m}^{2} \text {. }\end{array}$ \\
\hline 11 & Lottermann (2013) & $\begin{array}{l}\text { Análise das manifestações patológicas de um edifício } \\
\text { residencial localizado no município de Ijuí/RS. }\end{array}$ \\
\hline 12 & $\begin{array}{l}\text { Melo, Andrade e Paula } \\
\text { (2009) }\end{array}$ & $\begin{array}{l}\text { Análise de manifestações patológicas hidráulicas de } \\
\text { macrodrenagem revestidas em concreto. }\end{array}$ \\
\hline 13 & Brito (2017) & $\begin{array}{l}\text { Análise de manifestações patológicas na construção } \\
\text { civil, em uma instituição pública de ensino superior. }\end{array}$ \\
\hline 14 & Santos (2012) & $\begin{array}{l}\text { Análise de deterioração das estruturas de concreto } \\
\text { armado - Estudo em edifício comercial. }\end{array}$ \\
\hline
\end{tabular}


Research, Society and Development, v. 9, n. 7, e759974964, 2020

(CC BY 4.0) | ISSN 2525-3409 | DOI: http://dx.doi.org/10.33448/rsd-v9i7.4964

\begin{tabular}{|l|l|l|}
\hline 15 & Zuchetti (2016) & $\begin{array}{l}\text { Análise de manifestações patológicas e investigação } \\
\text { patológica em edifício corporativo de administração } \\
\text { pública no vale do Taquari/RS. }\end{array}$ \\
\hline
\end{tabular}

Fonte: Autores, 2020.

A partir dessa compilação de informações, realizou-se uma análise de dados com ilustrações representando os métodos construtivos que inibem o aparecimento de manifestação patológica em estruturas de concreto armado citado pelos autores, além de elencar medidas preventivas observadas na sua execução quando existir, medidas essas que asseguram e garantem uma via útil mais prolongada a estrutura.

Foram analisados 15 estudos de casos de obras executadas em concreto armado que possuíam algum tipo de manifestação patológica em sua estrutura. Como forma de organização, as manifestações patológicas foram registradas a partir das seguintes manifestações patológicas: fissura, trinca, corrosão da armadura, flambagem, carbonatação, eflorescência e manchas, sendo que das obras 15 obras analisadas elas estão presente pelo menos uma dessas obras, foi averiguado se contêm ou não a patologia referida de cada uma das manifestações patológicas elencadas, para apresentar as estatísticas. Posteriormente, foram calculadas as porcentagens que cada manifestação patológica representa num âmbito global em termo de mais incidentes. O cálculo é explicado na Tabela 1. 
Research, Society and Development, v. 9, n. 7, e759974964, 2020

(CC BY 4.0) | ISSN 2525-3409 | DOI: http://dx.doi.org/10.33448/rsd-v9i7.4964

Tabela 1: Exemplo de cálculo da incidência da manifestação patológica.

\begin{tabular}{|c|c|c|c|c|c|c|c|}
\hline Local & Fissura & Trinca & $\begin{array}{c}\text { Corr. } \\
\text { Armadura }\end{array}$ & Flambagem & Carbonatação & Eflorescência & Mancha \\
\hline Obra 1 & $X$ & & & & & & \\
\hline Obra 2 & $X$ & & & & & & \\
\hline Obra 3 & - & & & & & & \\
\hline Obra 4 & $X$ & & & & & & \\
\hline Obra 5 & - & & & & & & \\
\hline Obra 6 & $X$ & & & & & & \\
\hline Obra 7 & $X$ & & & & & & \\
\hline Obra 8 & $X$ & & & & & & \\
\hline Obra 9 & - & & & & & & \\
\hline Obra 10 & $X$ & & & & & & \\
\hline Obra 11 & $X$ & & & & & & \\
\hline Obra 12 & $X$ & & & & & & \\
\hline Obra 13 & $X$ & & & & & & \\
\hline Obra 14 & - & & & & & & \\
\hline Obra 15 & $X$ & & & & & & \\
\hline Incidência & $73 \%$ & & & & & & \\
\hline
\end{tabular}

Fonte: Autores, 2020.

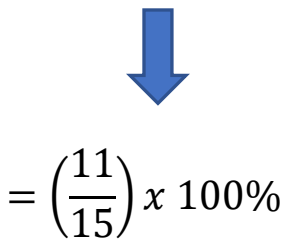

\section{Resultados e Discussão}

\subsection{Caracterização da literatura abordada}

A diferenciação dos resultados dessa pesquisa se fez por distinção de obras de gestão pública ou privada, assim como a distinção do meio entre rural ou urbano. O Quadro 3 apresenta esses dados e enquadram cada obra em sua devida locação e administração. 
Quadro 3: Determinação do meio e gestão das obras.

\begin{tabular}{|c|c|c|c|c|}
\hline \multirow{2}{*}{ Ambiente } & \multicolumn{2}{|c|}{ Meio } & \multicolumn{2}{c|}{ Gestão } \\
\cline { 2 - 5 } & Urbano & Rural & Pública & Privada \\
\hline Obra 01 & X & - & - & X \\
Obra 02 & - & X & - & X \\
Obra 03 & X & - & - & X \\
Obra 04 & X & - & - & X \\
Obra 05 & - & X & X & - \\
Obra 06 & X & - & - & X \\
Obra 07 & X & - & - & X \\
Obra 08 & X & - & - & X \\
Obra 09 & X & - & X & - \\
Obra 10 & X & - & - & X \\
Obra 11 & X & - & X & - \\
Obra 12 & X & - & - & X \\
Obra 13 & X & - & X & - \\
Obra 14 & - & X & X & - \\
Obra 15 & X & - & X & - \\
\hline Incidência & $80 \%$ & $20 \%$ & $40 \%$ & $60 \%$ \\
\hline
\end{tabular}

Fonte: Autores, 2020.

Analisando o Quadro 3, verificou-se que das obras analisadas, $80 \%$ localiza-se em meio urbano e apenas $20 \%$ em meio rural, um dado já esperado uma vez que é de grande notoriedade a alta incidência de análise em obras no meio urbano. Esse fator pode ser determinante em algumas patologias referentes à corrosão das armaduras, tal fato pode explicado pelas patologias referentes às maresias, responsáveis por inúmeras e variadas patologias. No que se refere à gestão no qual a construção se encontra, foi notado uma equivalência nos dados, na ocasião, definiu-se que $60 \%$ das edificações são de domínio privado e $40 \%$ público.

\subsection{Incidência das manifestações patológicas}

A seguinte Tabela 2 e o Figura 1 representam a ocorrência das manifestações patológicas, relacionando-as com as obras analisadas. 
Research, Society and Development, v. 9, n. 7, e759974964, 2020

(CC BY 4.0) | ISSN 2525-3409 | DOI: http://dx.doi.org/10.33448/rsd-v9i7.4964

Tabela 2: Incidência das manifestações patológicas nas estruturas de concreto armado.

\begin{tabular}{cccccccc}
\hline Local & Fissura & Trinca & $\begin{array}{c}\text { Corr. } \\
\text { Armadura }\end{array}$ & Flambagem & Carbonatação Eflorescência & Manchas \\
\hline Obra 01 & X & - & X & - & - & - & - \\
Obra 02 & X & - & X & - & - & - & X \\
Obra 03 & - & - & X & X & - & - & - \\
Obra 04 & X & - & X & - & X & X & X \\
Obra 05 & - & X & X & - & - & X & X \\
Obra 06 & X & X & X & X & X & - & X \\
Obra 07 & X & X & X & X & - & X & X \\
Obra 08 & X & X & X & - & - & - & X \\
Obra 09 & - & - & X & - & - & X & X \\
Obra 10 & X & X & X & - & X & - & - \\
Obra 11 & X & - & X & X & - & X & X \\
Obra 12 & X & X & X & - & - & - & - \\
Obra 13 & X & X & X & - & - & - & X \\
Obra 14 & - & - & X & - & - & X & - \\
Obra 15 & X & X & X & - & - & X & - \\
\hline Incidência & $73 \%$ & $53 \%$ & $100 \%$ & $27 \%$ & $20 \%$ & $47 \%$ & $60 \%$ \\
\hline
\end{tabular}

Fonte: Autores, 2020.

A Figura 1 apresenta o índice que se apresentam as manifestações patológicas nas obras analisadas, visto que o Tabela 2| amostra representado por 15 obras, as quais possuem em sua estrutura o uso de concreto armado.

Figura 1: Gráfico representativo de incidência das manifestações patológicas.

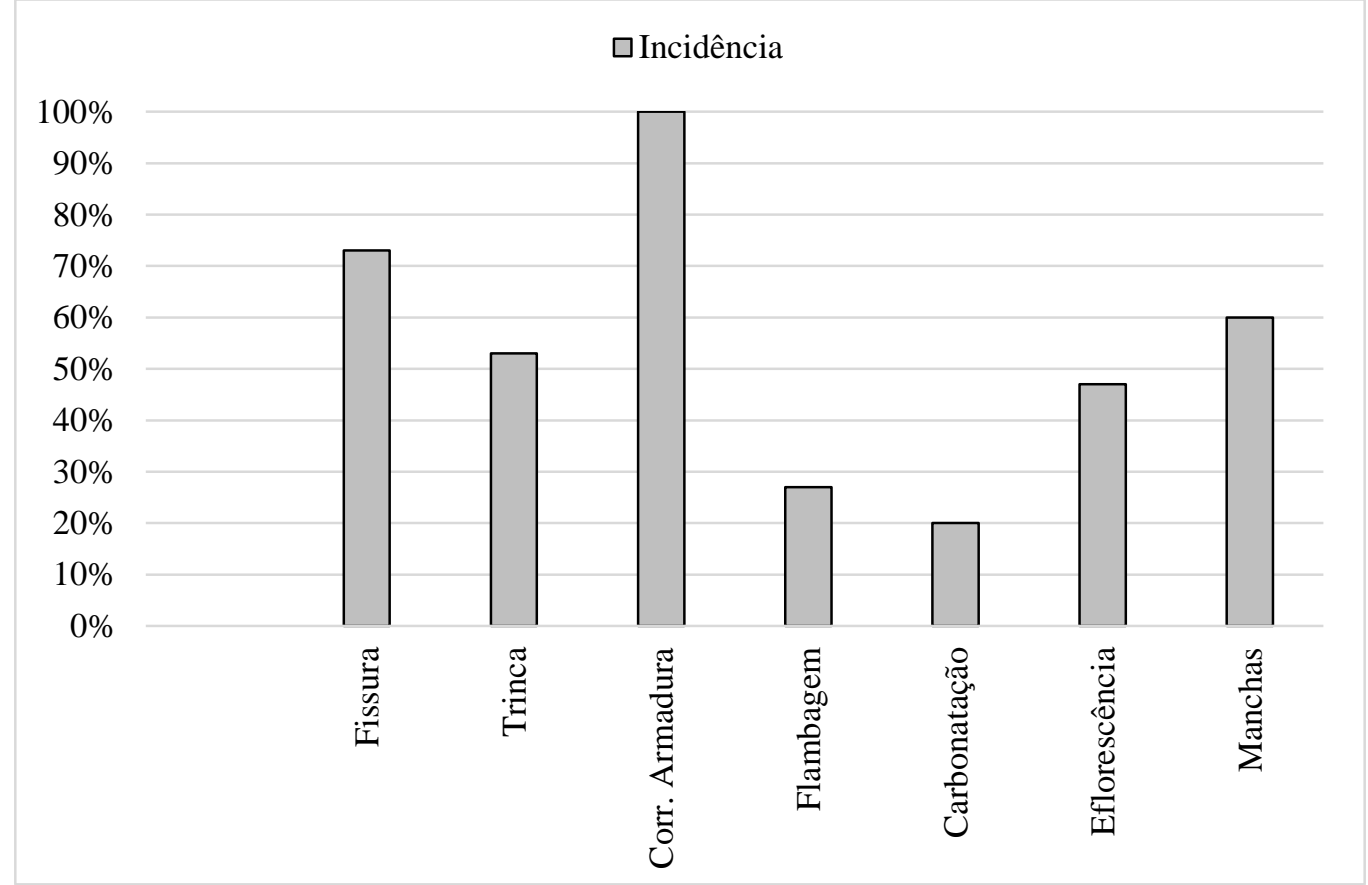

Fonte: Autores, 2020. 
Pela análise da Tabela 2 e Figura 1, verifica-se que a manifestação patológica mais presente foi a corrosão na armadura, representando 100\% dos casos. Em seguida fissuras, representando um índice de $73 \%$ de presença dentre as obras analisadas, as manchas aparecem em terceiro lugar das mais presentes, essa manifestação patológica está contida em $60 \%$ dos casos, logo após temos a trinca com 53\% de incidência e com menos expressão significativa temos as eflorescências, flambagem e carbonatação com 47\%, $27 \%$ e $20 \%$, respectivamente.

\subsection{Análise dos resultados obtidos por diferentes tipos de patologia}

A análise dos resultados procedeu por ordem das manifestações patológicas mais incidentes, sendo que essa sequência foi: Corrosão da armadura, Fissuras, Manchas, Trincas, Eflorescência, Flambagem e Carbonatação.

\subsubsection{Corrosão da armadura}

A corrosão da armadura foi a manifestação patológica mais frequente nas estruturas analisadas, ela representa $100 \%$ de ocorrência nos casos, ou seja, de todas as obras pesquisadas essa manifestação patológica se fez presente. Os motivos que causaram manifestação patológica foram os mais variados, tal anomalia se mostrou proveniente tanto de erros de execução, como de projetos, deixando a desejar principalmente em cobrimento, como também devido às fissuras e trincas, facilitando a infiltração de água e umidade.

Molin (1988) corrobora com o resultado encontrado, ao afirmar que já era de se esperar um alto índice na incidência de corrosão da armadura, visto que que o Brasil é um país continental, possuindo características úmidas. Zanzarine (2016) ainda atribui essa anomalia ao alto índice de obras executadas sem projetos estruturais e ausência de responsável técnico vistoriando as etapas de execução, como também destaca a baixa qualidade de mão de obra e o destrato com o acabamento de revestimento, uma vez que facilita a inserção de agentes agressores.

Nota-se nas Figuras 2 e 3 as complicações de corrosão de armadura extraídas dos estudos analisados. 
Research, Society and Development, v. 9, n. 7, e759974964, 2020

(CC BY 4.0) | ISSN 2525-3409 | DOI: http://dx.doi.org/10.33448/rsd-v9i7.4964

Figura 2: Falta de adensamento no momento da concretagem na obra 08.

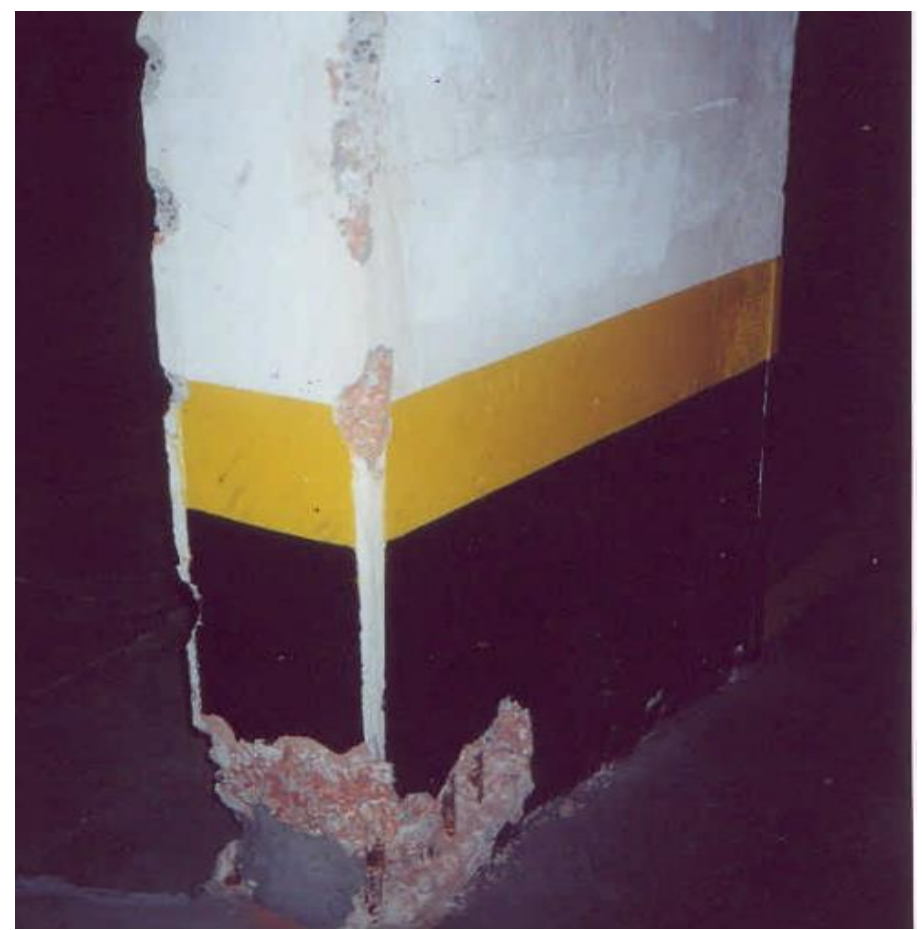

Fonte: Gonçalves (2015).

De acordo com Gonçalves (2015), a causa dessa manifestação patológica na Figura 2 é proveniente da ineficiência do método de adensamento do concreto e também à falta de limpeza da forma antes da concretagem.

Figura 3: Inexistência de cobriemento na parte inferior da viga na obra 12.

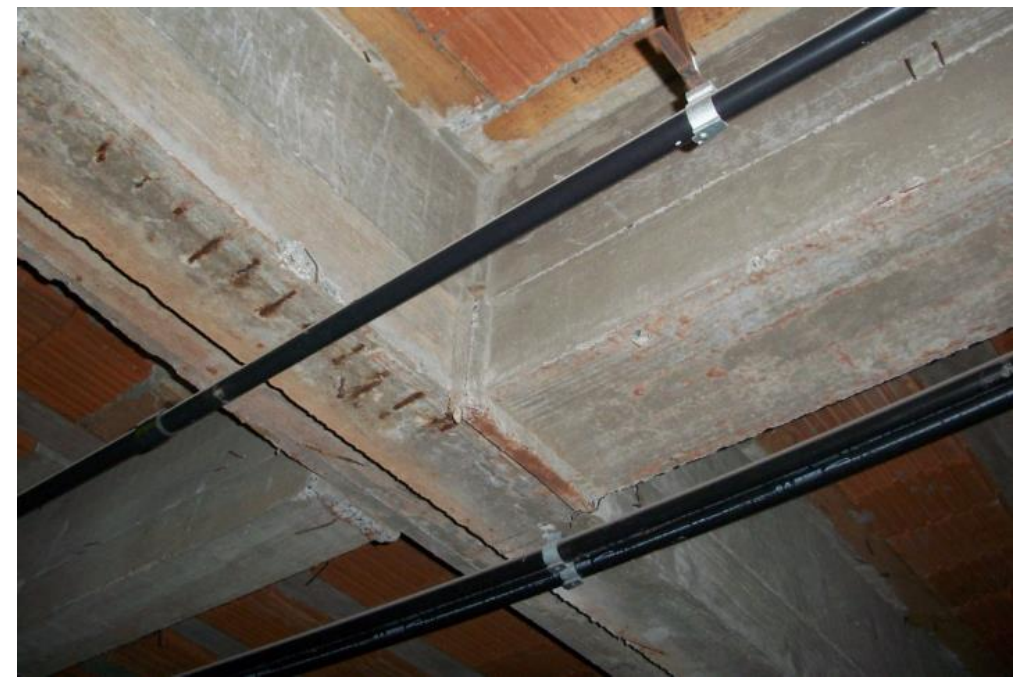

Fonte: Lottermann (2013). 
Feita uma análise das manifestações patológicas na obra 12 (Figura 3), Lottermann (2013) chegou à conclusão que um dos motivos que levaram a corrosão da armadura foi falta de espaçador na armadura, o que possibilita danos futuros. $\mathrm{O}$ autor verificou que os estribos das armaduras da vida estão aparentes, assim como a armadura longitudinal positiva, com isso estando vulnerável à ataques de agentes agressores.

\subsubsection{Fissuras}

No ranking das manifestações patológicas mais frequentes, tem-se as fissuras como a segunda manifestação patológica mais recorrentes nas obras analisadas nesse estudo. As fissuras se mostraram muito pertinentes, se manifestando em $73 \%$ dos casos, totalizando 11 aparições nas obras observadas. Muitas vezes as fissuras originam trincas que nessa avaliação aprece com uma margem de 53\% de presença na amostra, quando não tratadas, essas trincas despertam o aparecimento de rachaduras ou até mesmo fendas, quando é o caso de patologias vivas. Como de conhecimento, são diversos fatores que desencadeiam as fissuras, nos trabalhos estudados, foram detectadas fissuras de diversos sentidos e tamanhos, descritos assim como descritas nas Figuras 4 e 5.

Figura 4: Fissuras proveniente de junta de concretagem em pilar na obra 7.

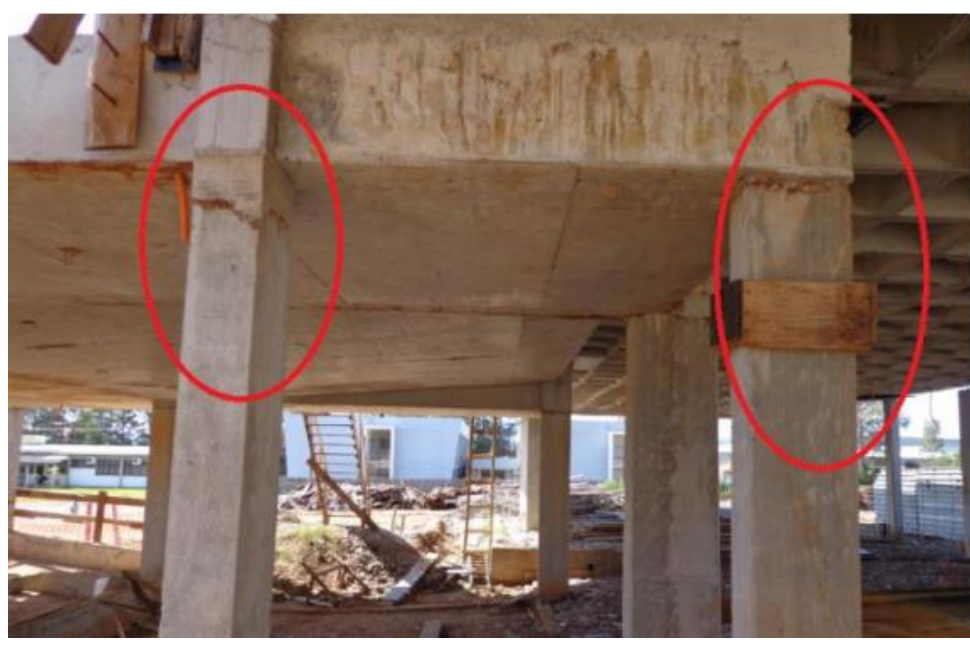

Fonte: Trindade (2015).

Helene (1998) corrobora com a presença da manifestação patológica localizada na face inferior da laje (junta da concretagem), apresentada na Figura 4, ao elencar que o cume do pilar com exagero de nata de cimento pode ser uma condição do aparecimento desse tipo de manifestação patológica, isso acontece devido a exsudação, resultando no enfraquecimento da 
estrutura. A Figura 5 também apresenta uma fissura, porém sua causa apresenta-se por outro motivo.

Figura 5: Fissura na parte externa da edificação na obra 15.

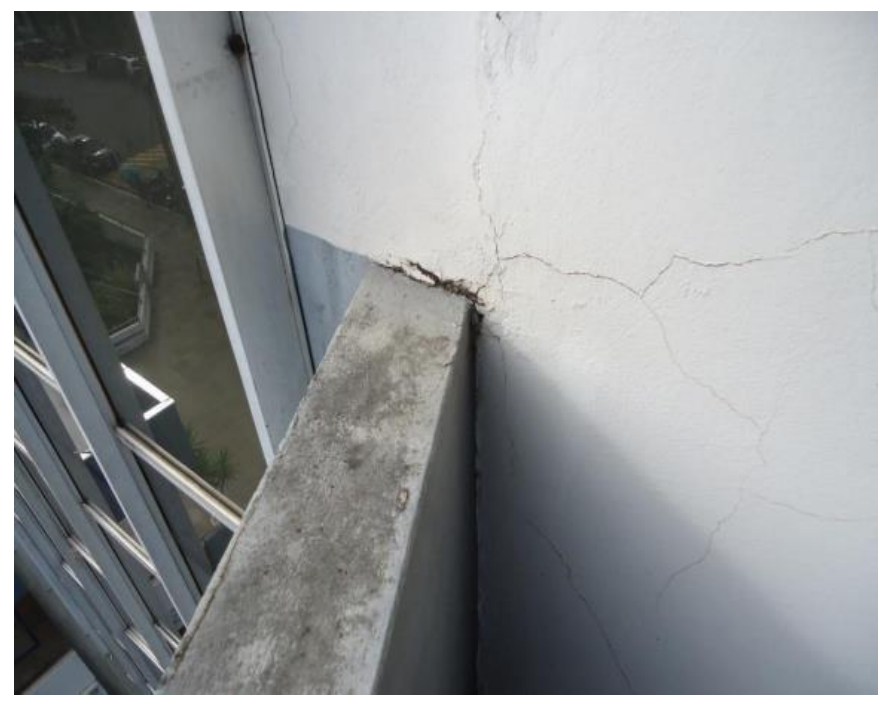

Fonte: Zuchetti (2015).

Na Figura 5, verifica-se a presença de fissuras que se cruzam em seu percurso. De acordo com Zuchetti (2015), essas anomalias evidenciam a retração hidráulica, entre os fatores que os causam destaca: falta de aderência, muitos níveis dispostos sobre a estrutura, além espessura ser acima do que a norma preconiza.

\subsubsection{Manchas}

Com um percentual expressivo, aparecem as manchas, representando $60 \%$ de presença nas obras analisadas nesse estudo. As manchas as vezes partem de eflorescências, que por sua vez representa um índice de $47 \%$, ou seja, aparecendo quase na metade de todas as obras analisadas.

A Figura 6 apresenta o aparecimento de manchas na obra 12. A construção em questão trata-se de uma obra de saneamento básico, as manchas, segundo Melo, Andrade e Paula (2009), provém do escoamento da água impura sobre a estrutura, a água por escoar da escada de drenagem, escoa diretamente na parede do canal que se localiza na interface lateral, provocando umidade no trecho onde essa água impura percorre, isso também vem acontecendo com as saídas das tubulações apresentando bolor e manchas das mais variadas tonalidades, com isso essa água poluída desgasta o concreto podendo até a causar perda de seção posteriormente. 
Figura 6: Manchas na parede lateral de um canal na obra 12.

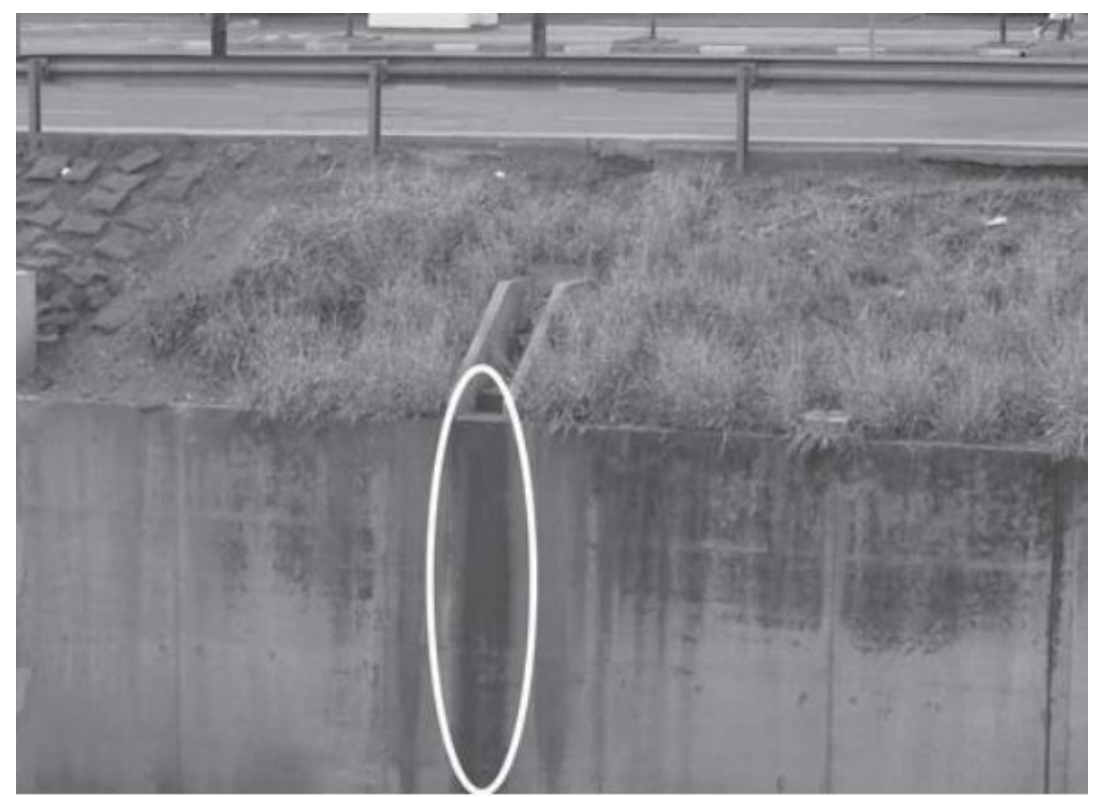

Fonte: Melo, Andrade e Paula (2009).

A Figura 7 também expõe um caso de mancha, manifestação patológica essa estudada na obra 8 por Gonçalves (2015), trata-se de uma construção de barramento de água. O autor listou as possíveis causas para o aparecimento desse tipo de manifestação patológica, atribuiu principalmente à falha na concretagem e má execução da cortina, uma vez que há a inexistência de drenagem do lençol freático e das águas.

Figura 7: Cortina de infiltração de água na obra 8.

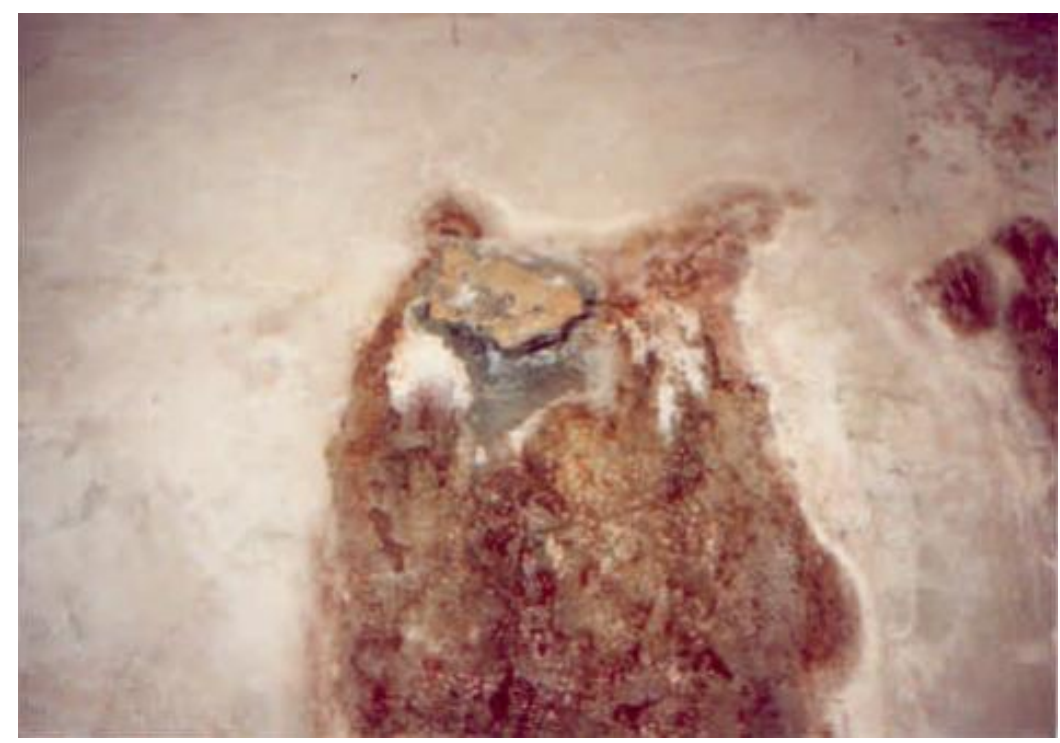

Fonte: Gonçalves (2015). 
Como metodologia de reparo na situação descrita, Gonçalves (2015) sugeriu a remoção completa do concreto que está em processo de desagregação, como também realizar uma regularização nas margens de abertura, fazer a limpeza nas barras de aço da armadura, solicita uma proteção galvânica para com a armadura, requisita que seja feita uma execução de rede de dreno com tubos PVC de 2" e um tamponamento com produtos impermeabilizante de boa qualidade em torno do tubo requerido.

\subsubsection{Trincas}

Esse tipo de manifestação patológica se fez presente em mais da metade dos casos observados, com 53\% de incidência. Esse tipo de anomalia muito comum nas construções de concreto armado é bem preocupante, visto que pode gerar risco de vida e da integridade da própria estrutura. Foi observado nas obras 5, 6, 7, 8, 10, 12, 13 e 15, sendo das mais variadas formas tamanhos e espessuras. A Figura 8 apresenta uma viga com uma trinca cortante ao seu eixo.

Figura 8: Trinca em viga de sustentação na obra 12.

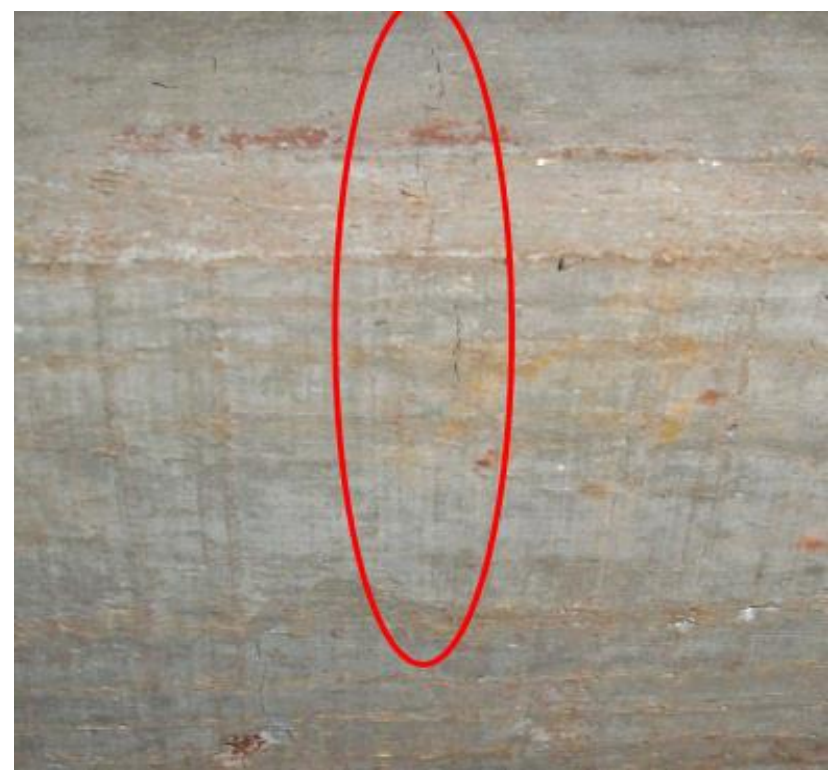

Fonte: Lottermann (2013).

Lottermann (2013) realizou uma descrição visual, no qual ele chegou à conclusão que se trata de uma trinca vertical na parte inferior da viga. A manifestação patológica se localiza no trecho central da viga em relação aos apoios de sustentação, a viga quando submetida a uma carga muito alta para sua capacidade de resistência delimitada no projeto, fica sujeita a trincas, 
dessa magnitude ou até mesmo mais expressivas. Como possíveis causas da manifestação patológica, o autor sugere que o principal motivo do aparecimento desse tipo de manifestação patológica é devido ao excesso de carregamento, e devido a sua forma de manifestação e sentido caracteriza-se como uma trinca por flexão.

\subsubsection{Eflorescência}

$\mathrm{Na}$ análise de dados, as manifestações patológicas do tipo eflorescência aparecem com um percentual de $47 \%$ de incidência, o que não é de causar espanto uma vez que essa manifestação patológica é tão comum nas construções de concreto armado. Santos (2012) afirma que geralmente quando se trata das patologias da construção civil, um fator influencia em outro, como é o caso que se pode observar na Figura 9. Com o efeito da eflorescência, umidade elevada e um cobrimento incorreto, levaram o pilar a sofrer deterioração com a perda de seção do aço, o que torna preocupante quanto à integridade física dos seus usuários.

Figura 9: Eflorescência no pilar, desencadeamento de séries de patologias na obra 14.

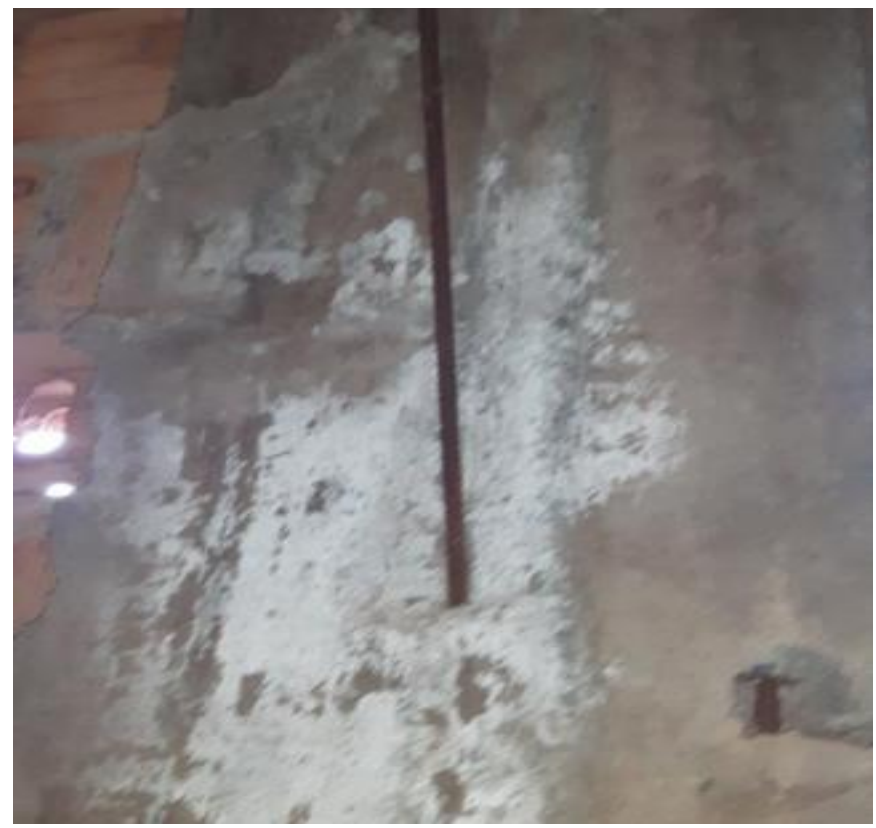

Fonte: Santos (2012).

Como nesse caso da obra 14 (Figura 9), o autor corrobora ao afirmar que a manifestação patológica do tipo eflorescência não prejudica apenas a estética, mas também é pode ser fator determinante na ação de oxidação da armadura. 


\subsubsection{Flambagem}

Pela análise das obras analisadas nesse estudo, verificou-se que a deflexão lateral (flambagem), apresenta-se com um índice um pouco mais discreto em relação as demais manifestação patológica construtivas, com $27 \%$ de incidência, estando presente nas obras 3, 6, 7 e 11. Esse tipo de manifestação patológica apesar de ter um percentual não tão expressivo, é muito rotineiro nas obras de concreto armado, acontece geralmente do mal dimensionamento de cálculo estrutural ou na maioria das vezes, a falta do dimensionamento (Moreira, 2009).

Figura 10: Pilar submetido a flambagem em processo de recuperação na obra 7.

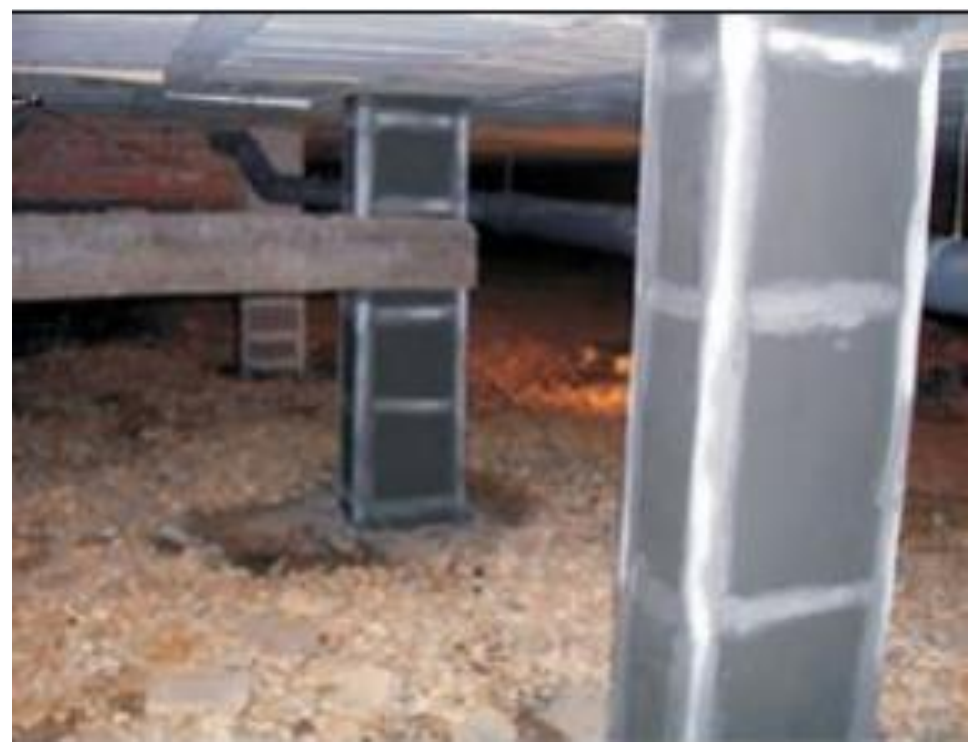

Fonte: Trindade (2015).

A Figura 10 apresenta um pilar submetido ao confinamento por meio da lâmina de fibra de carbono. Trindade (2015) afirma que, essa técnica de recuperação dos pilares que estão submetidos a esforços superiores ao quis suportam, é válido tanto para pilares esbeltos assim como peças mais robustas.

\subsubsection{Carbonatação}

A manifestação patológica com menos incidência dentre as demais é carbonatação como, representando apenas $20 \%$ dos estudos de caso analisados. A Figura 11 apresenta a manifestação patológica carbonatação na obra 10, de Fioriti (2016). 
Figura 11: Carbonatação ultrapassando o cobrimento da armadura na obra 10.

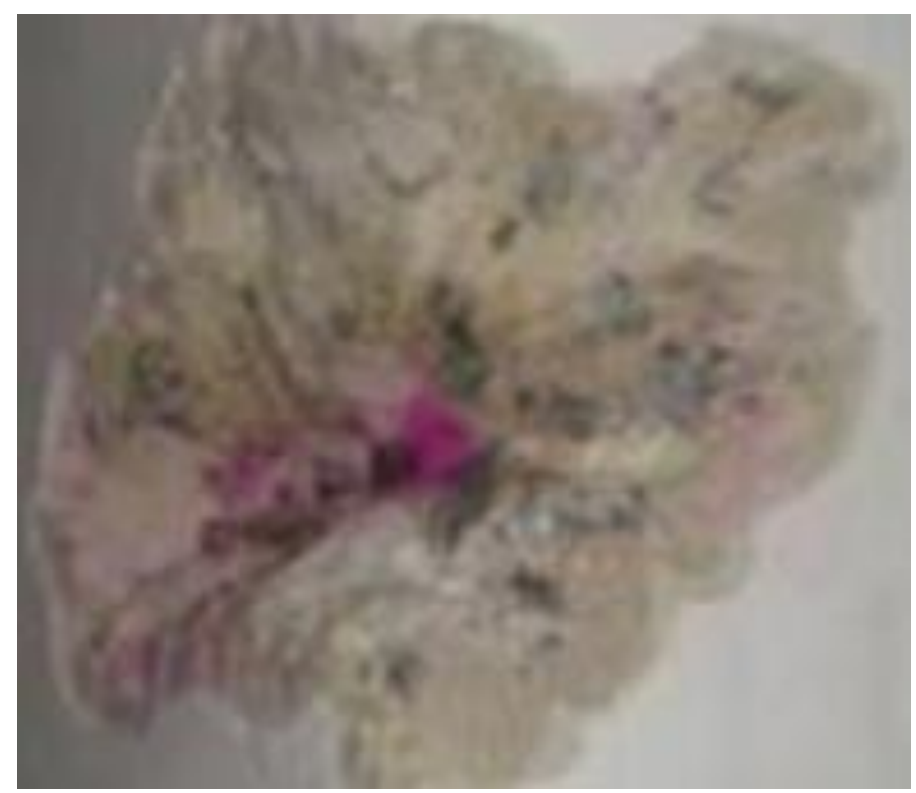

Fonte: Fioriti (2016).

A carbonatação apresentada na Figura 11, expõem um caso em que a manifestação patológica é vislumbrada pelo uso da fenolftaleína, a qual deixa a área não carbonatada com a cor rósea avermelhada. Contudo, a área que não houve alteração na coloração está comprometida a carbonatação, essa manifestação patológica ultrapassa o nível do cobrimento que envolve a armadura. Fioriti (2016) afirma que a carbonatação é um dos principais fatores que influenciam na corrosão da armadura, pois o concreto se torna propício a ser adentrado com facilidade pelos agentes externos e intempéries.

Fioriti (2016) sugere como medida para o combate da patologia, o aumento da sessão do pilar, uma vez que no estudo realizado foi visto que a taxa de armadura era superior ao necessário naquela peça. Em outro estudo similar ao de Fioriti (2016), Silva (2018) em seus estudos apresenta a influência da carbonatação em estrutura de concreto armadura (Figura 12). 
Figura 12: Ataque da carbonatação na obra 4.
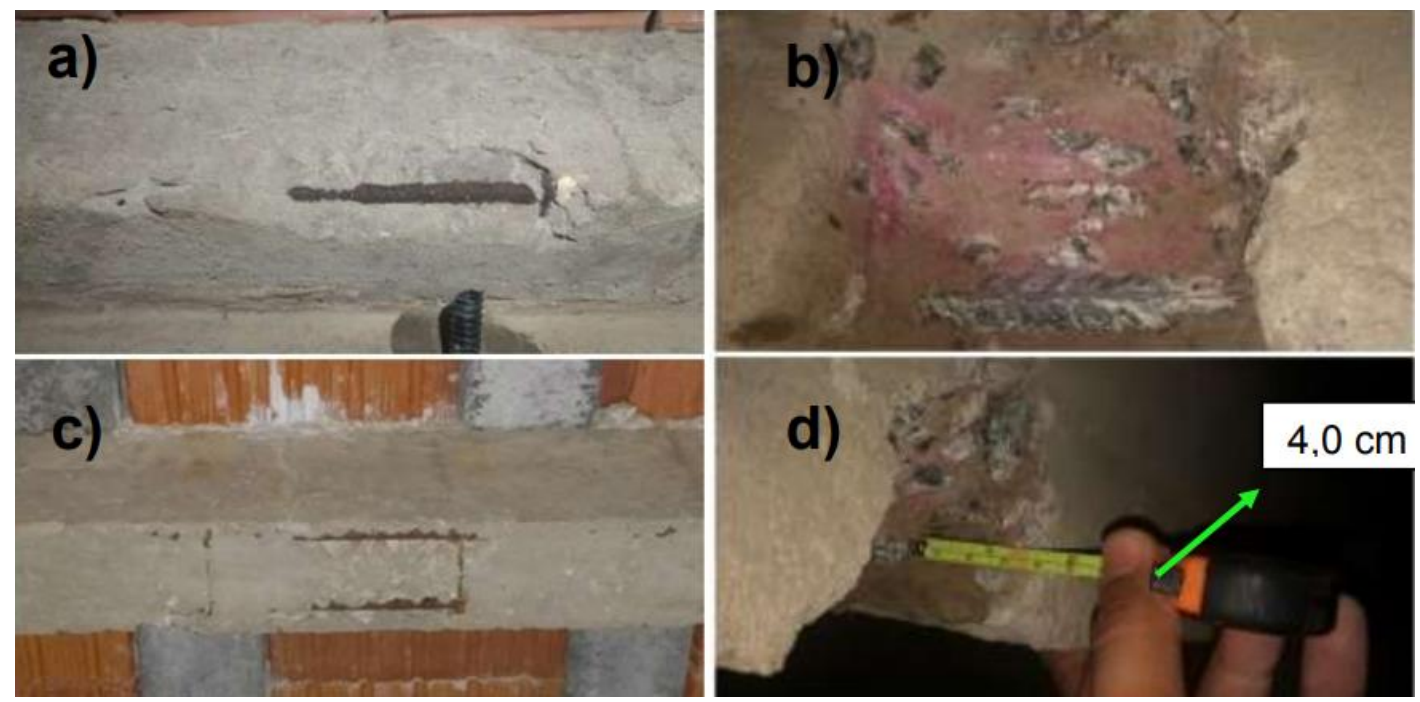

Fonte: Silva (2018).

Nessa situação, são ilustradas vigas a quais estão sob efeito da carbonatação, a Figura 12a) e 12c) apresentam estribos já sob o efeito da corrosão da armadura, anomalias essas advinda da carbonatação do concreto. Silva (2018) afirma que foram feitos ensaios com a fenolftaleína, contudo o índice de carbonatação se apresentou tão alto que não apresentaram nenhuma alteração na cor, exceto uma rápida coloração rósea avermelhada na Figura 12b. Para solucionar o problema, o autor propõe aumento na sessão do concreto, até que essas peças possam ter uma maior vida útil.

\section{Considerações Finais}

Com a realização do levantamento de banco de dados das manifestação patológica frequentes em estruturas de concreto armado, verificou-se que das manifestações patológicas analisadas, a mais frequente nas obras é a corrosão da armadura, com presença em $100 \%$ dos casos analisados, um dado que é preocupante se levado em consideração o perigo que essa patologia carrega consigo em termos de risco à integridade física da própria edificação e vida dos seus usuários. Em seguida destacam-se as manifestações patológicas do tipo fissura e manchas com $73 \%$ e $60 \%$, respectivamente, manifestação patológica como as fissuras possibilitam o aparecimento de demais patologias, inclusive, a corrosão da armadura, tão presente nas obras brasileiras como mostrado nessa pesquisa.

As manchas por sua vez, também fazem o papel de despertar a geração de novas manifestações patológicas, como: bolores, desagregação de revestimento e desplacamento 
(CC BY 4.0) | ISSN 2525-3409 | DOI: http://dx.doi.org/10.33448/rsd-v9i7.4964

cerâmico. É válido ressaltar que embora as quinze obras estudadas sejam um número representativo, não se deve tê-las como parâmetro absoluto, visto que há uma grande variação de espaço, temperatura e umidade em torno de toda a extensão brasileira, além do mais a amostra possui uma pequena amplitude. Com a pesquisa bibliográfica, foi visto que dos problemas mencionados desacatam-se: Trinca (53\%); Eflorescencia (47\%); Flambagem (27\%) e Carbonatação (20\%), todas essas manifestações patológicas agravam na durabilidade da estrutura deixando-a com uma vida útil menor, transformando o ambiente de vivência em um prejuízo financeiro, quer seja público como privado.

Espera-se que o trabalho corrobore para maior incentivo aos construtores, projetistas e usuários de concreto armado a se atentarem mais ao realizar obras com esse material, que obedeçam aos procedimentos e normas a fim de garantir maior durabilidade e estética as edificações desse país. A principal dificuldade encontrada nesse estudo foi a pouca quantidade de trabalhos que abordassem todas as patologias de interesse nesse estudo em apenas uma obra. Como sugestão para futuros trabalhos, indica-se trabalhos de revisão bibliográfica que tenha como objetivo uma análise física e química das patologias abordadas nesse estudo.

\section{Referências}

Andolfato, R. P. (2002). Controle tecnológico básico do concreto. In: Núcleo de Ensino e Pesquisa da Alvenaria Estrutural, Ilha Solteira: [s. N.].

Andrade, T., \& Silva, A. J. D. C. (2005). Patologia das estruturas. In: Concreto: ensino, pesquisa e realizações. São Paulo: IBRACON, 953-983.

Associação Brasileira de Normas Técnicas - ABNT. (2013). NBR 15575 - Edificações habitacionais - Desempenho. Recuperado de: https://hosting.iar.unicamp.br/lab/luz/ld/ normas\%20e\%20relat\%f3rios/NRs/NR\%2015575/NBR_15575-5_2013_Final\%20Sistemas\% 20de\%20Cobertura.pdf.

Associação Brasileira de Normas Técnicas - ABNT. (2014). NBR 6118: Projeto de estruturas de concreto -procedimento. Recuperado de: https://docs.google.com/viewer?a=v\&pid= sites\&srcid=ZGVmYXVsdGRvbWFpbnxjb25jcmV0b2FybWFkb3VuaWNhcHxneDo2YjRm NmM5MTA5NGE1OTE1. 
Bastos, P. S. D. S. (2006). Fundamentos do concreto armado. Bauru: UNESP.

Borges, M. G. (2008). Manifestações patológicas incidentes em reservatórios de água elevados executados em concreto armado. (Trabalho de Conclusão do Curso, Universidade Estadual de Feira de Santana - UEFS).

Brito, T. F. D. (2017). Análise de Manifestações Patológicas na Construção Civil pelo Método GUT: estudo de caso em uma instituição pública de ensino superior. (Trabalho de Conclusão de Curso, Universidade Federal da Paraíba - UFPB).

Cirino, M., Oliveira, B., Pereira, S., Cordeiro, S., Morais, J., Silva, E., \& Barboza, E. (2020). Avaliação das manifestações patológicas das edificações do departamento de engenharia de alimentos da Universidade Federal do Ceará. Research, Society and Development, 9(7), e481974424.

Corsini, R. (2010). Trinca ou fissura. Téchne, São Paulo, (160), 56-60.

Dias, N. A. A. (2012). Geopolímeros: contributos para a redução das eflorescências (Dissertação de Mestrado, Escola de Engenharia da Universidade do Minho).

Ferreira, R. (2018). Patologias em estruturas de concreto armado. (Trabalho de Conclusão de Curso, Faculdade de Ciências Humanas e Sociais da Fundação Carmelitana Mário Palmério FUCAMP).

Freire, K. R. R. (2005). Avaliação do Desempenho de Inibidores de Corrosão em Armaduras de Concreto. (Dissertação de Mestrado - Curso de Engenharia e Ciências dos Materiais, Universidade Federal do Paraná).

Gil, C.A. (2008). Como elaborar projetos de pesquisa. São Paulo: Atlas.

Gonçalves, E. A. B. (2015). Estudo de patologias e suas causas nas estruturas de concreto armado de obras de edificações. Rio de Janeiro: UFRJ.

Granato, J. E. (2012). Patologia das construções. São Paulo: AEA Cursos. 
Helene, P. (2001). Introdução da vida útil no projeto das estruturas de concreto NB/2001. In Workshop sobre durabilidade das construções. São José dos Campos.

Helene, P. R. L. (1986). Corrosão em armaduras para concreto armado. São Paulo: Pini/Ipt. Hibbeler, R. C. (2010). Resistência dos materiais. Pearson Educación.

Hoppe Filho, J. (2008). Sistemas cimento, cinza volante e cal hidratada: mecanismo de hidratação, microestrutura e carbonatação de concreto (Doctoral dissertation, Universidade de São Paulo - USP).

Iantas, L. C. (2010). Estudo de caso: análise de patologias estruturais em edificação de gestão pública. (Monografia de Especialização em Construção de Obras Públicas, Universidade Federal do Paraná).

Kaefer, L. F. (1998). A evolução do concreto armado. São Paulo, 43p.

Lottermann, A. (2013). Patologias em estruturas de concreto: Estudo de caso. (Trabalho de Conclusão de Curso em Engenharia Civil, Universidade Regional do Noroeste do Estado de Rio Grande do Sul).

Martins, J. F. A., \& Fioriti, C. F. (2016). Investigação de manifestações patológicas em sistemas estruturais de concreto armado: Estudo de caso em edificação pública. Revista Brasileira de Iniciação Científica, 3(4), 1-13.

Melo, V. S., de Andrade, H., \& de Paula, A. (2009). Patologias em estruturas hidráulicas de macrodrenagem revestidas em concreto. Construindo, 1(01), 32-37.

Menezes, R. R., Ferreira, H. S., Neves, G. D. A., \& Ferreira, H. C. (2006). Sais solúveis e eflorescência em blocos cerâmicos e outros materiais de construção-revisão. Cerâmica, 52(321), 37-49. 
Milani, C. J., Boesing, R., Philippsen, R. A., \& Miotti, L. A. (2012). Processo produtivo de elementos pré-moldados de concreto armado: detecção de manifestações patológicas. Risco Revista de Pesquisa em Arquitetura e Urbanismo (Online), (15), 82-91.

Molin, D. (1988). Fissuras em estruturas de concreto armado: análise das manifestações típicas e levantamentos de casos ocorridos no estado do Rio Grande do Sul. (Doctoral dissertation, Dissertação de Mestrado, Universidade Federal do Rio Grande do Sul).

Morais, R. S. (2017). Patologias geradas por erros de execução de estrutura de concreto armado: causas, medidas preventivas e consequências. (Trabalho de Conclusão de Curso, Universidade Regional do Cariri - URCA).

Moreira, K. (2009). Estudo das manifestações patológicas na produção de préfabricados de concreto. 2009. (Dissertação de Mestrado do Programa de Pós-graduação em Engenharia Mecânica e de Materiais, Universidade Tecnológica Federal do Paraná).

Munaro, R., \& Possan, E. (2017). Falha de concretagem de pilares e suas consequências na estrutura da edificação. In: Simpósio Paranaense de Patologia das Construções.

Nascimento, F. B. C. (2015). Corrosão em armaduras de concreto. Caderno de GraduaçãoCiências Exatas e Tecnológicas-UNIT-ALAGOAS, 3(1), 177-188.

Olivari, G. (2003). Patologia das edificações. (Trabalho de Conclusão de Curso, Universidade Anhembi Morumbi).

Oliveira Buffoni, S. S. (2004). Estudo da Flambagem de Armaduras Longitudinais em Pilares de Concreto Armado. (Tese de Doutorado, Pontifica Universidade Católica do Rio de Janeiro).

Oliveira, A.M. (2012). Fissuras e rachaduras causadas por recalque diferencial de fundações. (Monografia, Especialização em Gestão em Avaliações e Perícias - Universidade Federal de Minas Gerais, Minas Gerais).

Pereira, A. S., Shitsuka, D. M., Parreira, F. J. \& Shitsuka, R. (2018). Metodologia da pesquisa científica. [e-book]. Santa Maria. 1 Ed. UAB/NTE/UFSM. Recuperado de: 
https://repositorio.ufsm.br/bitstream/handle/1/15824/Lic_Computacao_MetodologiaPesquisaCientifica.pdf? sequence $=1$.

Pfeil, W. (1984). Concreto Protendido-Introdução (2ºd). LTCE, Rio de Janeiro, 221p.

Possan, E., \& Munaro, R. (2017). Análise da falha de concretagem de pilares de uma edificação: Estudo de caso. Revista Técnico-Científica, 5(9), 1-15.

Rios, E. C. C., Aguado, R. A. B., dos Santos Lisboa, D. C., Rocha, L. N., de Santana, C. G., \& Muller, R. M. L. (2020). Carbonation in armed concrete structures: Diagnosis of the carbonation process in reinforced concrete slabs present in the parking lot of a commercial building in the city of São Luís-MA. Brazilian Journal of Development, 6(3), 15846-15869.

Santos, G. V. D. (2014). Patologias devido ao recalque diferencial em fundações. Centro Universitário de Brasília - UniCEUB Faculdade de Tecnologia e Ciências Sociais AplicadasFATECS, Brasília.

Santos, M. R.G. (2012). Deterioração das Estruturas de Concreto Armado - Estudo de Caso. (Monografia apresentada ao Curso de Especialização em Construção Civil, Escola de Engenharia da Universidade Federal de Minas Gerais).

Silva, H.A.S. (2018). Análise das patologias construtivas em uma residência unifamiliar do bairro Tiradentes na cidade de Juazeiro do Norte-CE. (Trabalho de Conclusão de Curso, Universidade Regional do Cariri - URCA).

Silva, L. K. (2011). Levantamento de manifestações patológicas em estruturas de concreto armado no estado do Ceará. (Trabalho de Conclusão de Curso, Universidade federal do Ceará - UFC).

Silva, L. M. S. B. D. (1996). Desenvolvimento de um sistema especialista para o diagnóstico de fissuras em concreto armado. (Dissertação de Mestrado, Universidade Federal do Rio Grande do Sul). 
Souza, V. C. M., \& Ripper, T. (1998). Patologia, recuperação e reforço de estruturas de concreto. Pini.

Trindade, D. D. S. (2015). Patologias em estruturas de concreto armado. (Trabalho de Conclusão de Curso, Universidade Federal de Santa Maria - UFSM).

Zanzarini, J. C. (2016). Análise das causas e recuperação de fissuras em edificação residencial em alvenaria estrutural-estudo de caso. (Trabalho de Conclusão de Curso, Universidade Tecnológica Federal do Paraná).

Zuchetti, P. A. B. (2016). Patologias da construção civil: investigação patológica em edifício corporativo de administração pública no Vale do Taquari/RS. (Monografia de Graduação em Engenharia Civil, Universidade do Vale do Taquari).

\section{Porcentagem de contribuição de cada autor no manuscrito}

João Marcos Pereira de Morais - 30\%

Andreane Martin da Silva - 20\%

Eliezio Nascimento Barboza - 20\%

Eduarda Morais da Silva - 15\%

Bruno Barbosa de Oliveira - 15\% 